\title{
Maus-tratos infantis na perspectiva de acadêmicos de Odontologia
}

\author{
Claudia de Abreu Busato*; Teresa Cristina Rangel Pereira**; Renata Oliveira Guaré*** \\ * Docente da Faculdade de Odontologia da Universidade do \\ Planalto Catarinense \\ ** Docente da Faculdade de Odontologia da Universidade \\ Federal do Espírito Santo \\ *** Docente da Faculdade de Odontologia da Universidade \\ Cruzeiro do Sul
}

Recebido em 14/02/2017. Aprovado em 18/05/2017.

\begin{abstract}
RESUMO
A violência infantil não ocorre apenas em países em desenvolvimento e é tão frequente que por vezes é banalizada. Crianças e adolescentes são alvos fáceis para atos de violência por serem frágeis e dependentes. O objetivo desta pesquisa foi verificar, por meio de questionários, o conhecimento de estudantes de Odontologia em relação aos maus-tratos na infância e adolescência. Todos os acadêmicos matriculados nos cursos de Odontologia das Universidades do Planalto Catarinense e Federal do Espírito Santo foram convidados a participar do estudo. O questionário abordou conceito e características de maus-tratos, conduta frente aos mesmos, conhecimento do Estatuto da Criança e do Adolescente (ECA) e responsabilidade do cirurgiãodentista na notificação de maus-tratos. Os dados foram analisados por meio de estatísticas descritivas. Participaram da pesquisa 363 alunos, 146 de Lages e 217 de Vitória. Destes, 265 (73,0\%) eram do gênero feminino, com idade média de 21,38 \pm 3,01 anos. Durante a graduação, 34,9\% dos alunos afirmaram não ter recebido nenhuma informação sobre maus-tratos na infância e adolescência. Apesar disto, a maioria (86,8\%) sente-se capaz de diagnosticar casos de maus-tratos. Os estudantes citaram alterações nos tecidos moles $(65,3 \%)$ e traumatismos dentários $(48,5 \%)$, como caracetrísticas relacionadas aos maus-tratos. Em relação à denúncia, apenas 30,3\% referem o Conselho Tutelar como esfera competente e 35,5\% sabem o significado da sigla ECA. Foi observado que os acadêmicos das duas instituições conseguem identificar os sinais de maustratos, mas precisam de maiores informações em relação à notificação dos mesmos.

Descritores: Maus-tratos Infantis. Educação em Odontologia. Estudantes de Odontologia.
\end{abstract}

\section{INTRODUÇÃO}

Um dos grandes desafios da atualidade é enfrentar a violência, principalmente quando dirigida contra crianças e adolescentes, que deveriam estar protegidas, principalmente em seus lares. Casos de infanticídio, exploração do trabalho infantil, escravidão, abandono, espancamentos e mutilação ocorrem de longa data e se perpetuam nos dias atuais ${ }^{1}$. Em 2009, segundo a Sociedade Internacional de Prevenção ao Abuso e Negligência na Infância, cerca de 18 mil crianças foram vítimas de violência por dia, 750 por hora e 12 por minuto ${ }^{2}$. Segundo a UNICEF $(2012)^{3}$ cerca de 3.500 crianças e adolescentes morrem anualmente por maus-tratos 
físicos ou negligência. Em 2012, foram 130.029 casos de maus-tratos na infância registrados no telefone da Secretaria de Direitos Humanos da Presidência da República que recebe denúncias (disque 100) ${ }^{4}$.

O artigo 245 do Estatuto da Criança e do Adolescente (ECA), torna indiscutível a obrigação de qualquer cidadão a comunicar os casos de maustratos, porém estabelece penalização administrativa somente para médicos, educadores e dirigentes atuantes que não comunicarem à autoridade competente os casos envolvendo suspeita ou confirmação de maus-tratos contra a criança ou adolescente, com multa de três a vinte salários de referência, aplicando-se o dobro em caso de reincidência 5 .

Um dos problemas para a subnotificação é o fato dos profissionais de saúde apresentarem dificuldades para identificar os casos, por falta de informações básicas que permitam o diagnóstico ${ }^{6,7}$. A violência contra a criança e adolescente é um problema social e multifatorial, assim sendo, é fundamental que estudantes da área da saúde assumam uma postura mais dinâmica frente a esta realidade, não apenas identificando as lesões mais comuns, como também denunciando os possíveis agressores.

Esta pesquisa objetiva verificar o conhecimento de estudantes de Odontologia de duas instituições frente aos maus-tratos na infância e adolescência em relação ao reconhecimento dos sinais de abusos, bem como a quem notificar.

\section{MATERIAIS E MÉTODOS}

A pesquisa foi realizada após aprovação pelo Comitê de Ética em Pesquisa da Universidade Cruzeiro do Sul - UNICSUL (Protocolo CEP 053/2014) com estudantes dos cursos de Odontologia da Universidade do Planalto Catarinense (UNIPLAC), na cidade de Lages/SC, e Universidade Federal do Espírito Santo (UFES), em Vitória/ES, caracterizando-se como transversal observacional quantitativa e multicêntrica.

Todos os acadêmicos matriculados (UNIPLAC 163 alunos e UFES 300 alunos) foram convidados a participar do estudo, após assinatura do Termo de Consentimento Livre e Esclarecido (TCLE). Os dados foram coletados no período de agosto a novembro de 2014. Para a coleta dos dados optou-se por encontrar os alunos na sala de aula no início de um período, sendo solicitado ao professor um momento para explicar os objetivos da pesquisa, em seguida os alunos eram convidados a participar, ressaltando a não obrigatoriedade e o anonimato no preenchimento do questionário. Os alunos que aceitaram participar recebiam o TCLE e o questionário, deixando-os à vontade para responder e devolvê-los aos pesquisadores.

O questionário utilizado (quadro 1) contém uma introdução com dados demográficos (idade, gênero, semestre que estão cursando), uma segunda parte referente ao conceito e características de maustratos e a terceira associada à conduta frente a caso de maus-tratos, conhecimento do Estatuto da Criança e do Adolescente (ECA) e responsabilidade do cirurgião-dentista (CD) na notificação de maustratos.

Os dados foram analisados por meio de estatísticas descritivas.

\section{RESULTADOS}

Participaram da pesquisa 146 alunos de Lages e 217 alunos de Vitória, totalizando 363 alunos, sendo $265(73 \%)$ do gênero feminino, com idade média de $21,38 \pm 3,01$.

Dos participantes, $91(25,1 \%)$ estavam no primeiro ano, $64(17,6 \%)$ no segundo, $76(21 \%)$ no terceiro, $72(19,8 \%)$ no quarto e $60(16,5 \%)$ no último ano.

Em relação à distribuição dos alunos quanto à fonte de informação sobre violência infantil, observase na tabela 1, a época em que a informação foi recebida na graduação.

A tabela 2 se refere à definição de maus-tratos, na qual as respostas foram categorizadas de acordo com art. 136 do Código Penal Brasileiro ${ }^{8}$.

Os dados relativos à capacidade do aluno de identificar maus-tratos e as características gerais e bucais que podem indicar este tipo de violência estão expressos na tabela 3. As categorias foram divididas, de acordo com as respostas dadas pelos acadêmicos, em características gerais: alterações comportamentais, lesões sem explicações, machucados na face 
e no corpo, falta de cuidado; e em relação às características bucais foram categorizadas em: dentes fraturados, falta de cuidado com higiene bucal, lesões nos tecidos moles bucais e hábitos deletérios.

Os dados referentes a como agir frente a situações de maus-tratos foram divididos entre denunciar ao Conselho Tutelar, à Delegacia da Infância, às autoridades (quando aluno não citava nenhuma instituição específica) e outros (quando se referia à família, escola, psicólogo), a responsabilidade do $C D$ nestes casos e o conhecimento do ECA estão expostos na tabela 4.

Nas questões finais sobre se já havia presenciado uma situação de maus-tratos, $23(15,7 \%)$ alunos de Lages e 60 (27,6\%) de Vitória afirmaram ter presenciado tais situações. Quanto à receber mais informações sobre este assunto, 345 alunos $(95,1 \%)$ responderam que sim e apenas 18 (4,9\%) não.

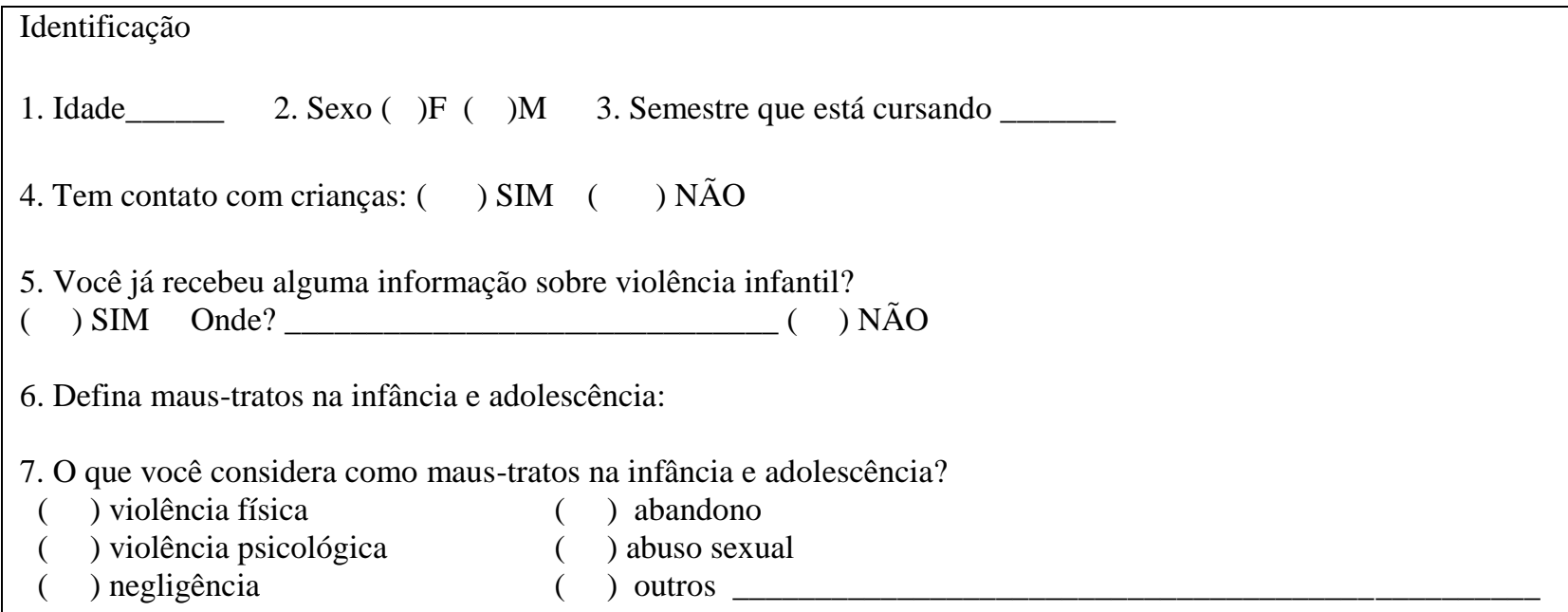

8. Seria capaz de identificar casos de maus-tratos infantis? （ ) SIM （ ) NÃO

9. Cite características que podem sinalizar que a criança ou o adolescente sofreu maus-tratos:

10. Cite características bucais que podem estar relacionadas aos maus-tratos na infância e adolescência:

11. Como agir diante de casos de maus-tratos:

12. Você sabe o que é o ECA? ( )SIM O que é?

13. Você já presenciou ou suspeitou um caso de maus-tratos? （ ） SIM （ ) NÃO

14. O cirurgião-dentista tem responsabilidade de notificar casos suspeitos ou confirmados de maus-tratos?

( ) SIM ( ) NÃO

15. Gostaria de receber mais informações sobre este assunto? ( ) SIM （ ） NÃO

\section{Quadro 1- Questionário utilizado no estudo}


Tabela 1- Distribuição dos estudantes em relação à fonte de informação sobre violência infantil

\begin{tabular}{|c|c|c|c|c|c|c|c|c|c|c|c|}
\hline \multirow[b]{2}{*}{ Fonte } & \multicolumn{2}{|c|}{$1 .^{\circ}$ ano } & \multicolumn{2}{|c|}{$2 .^{\circ}$ ano } & \multicolumn{2}{|c|}{$3^{\circ}$ ano } & \multicolumn{2}{|c|}{$4 .^{\circ}$ ano } & \multicolumn{2}{|c|}{$5 .^{\circ}$ ano } & \multirow[b]{2}{*}{$\begin{array}{c}\text { Total } \\
(\%)\end{array}$} \\
\hline & $\begin{array}{c}\text { Lages } \\
\text { n }\end{array}$ & $\begin{array}{c}\text { Vitória } \\
\text { n }\end{array}$ & $\begin{array}{c}\text { Lages } \\
\text { n }\end{array}$ & $\begin{array}{c}\text { Vitória } \\
\text { n }\end{array}$ & $\begin{array}{l}\text { Lages } \\
\text { n }\end{array}$ & $\begin{array}{c}\text { Vitória } \\
\text { n }\end{array}$ & $\begin{array}{c}\text { Lages } \\
\text { n }\end{array}$ & $\begin{array}{c}\text { Vitória } \\
\text { n }\end{array}$ & $\begin{array}{c}\text { Lages } \\
\text { n }\end{array}$ & $\begin{array}{c}\text { Vitória } \\
\mathbf{n}\end{array}$ & \\
\hline Graduação & 0 & 2 & 1 & 1 & 2 & 4 & 12 & 8 & 17 & 20 & $\begin{array}{c}67 \\
(18,5)\end{array}$ \\
\hline Escola & 10 & 13 & 5 & 5 & 2 & 9 & 0 & 5 & 1 & 1 & $\begin{array}{c}51 \\
(14,1)\end{array}$ \\
\hline $\begin{array}{l}\text { Meios de } \\
\text { comunicação }\end{array}$ & 20 & 18 & 11 & 14 & 4 & 15 & 6 & 25 & 2 & 13 & $\begin{array}{c}128 \\
(35,3)\end{array}$ \\
\hline Família & 0 & 8 & 0 & 4 & 0 & 7 & 0 & 2 & 0 & 5 & $26(7,2)$ \\
\hline $\begin{array}{l}\text { Não } \\
\text { receberam } \\
\text { informação }\end{array}$ & 15 & 12 & 12 & 15 & 16 & 20 & 9 & 14 & 9 & 5 & $\begin{array}{c}127 \\
(34,9)\end{array}$ \\
\hline $\begin{array}{l}\text { Não } \\
\text { respondeu }\end{array}$ & 0 & 0 & 0 & 0 & 0 & 1 & 0 & 0 & 0 & 0 & $1(0,3)$ \\
\hline
\end{tabular}

Tabela 2 - Definição de maus-tratos pelos estudantes

\begin{tabular}{|c|c|c|c|}
\hline \multirow[b]{2}{*}{ Definição de maus-tratos } & \multirow{2}{*}{$\begin{array}{l}\text { Lages } \\
\text { n }(\%)\end{array}$} & Vitória & Total \\
\hline & & n $(\%)$ & n $\quad(\%)$ \\
\hline Incorreta & $43(29,4)$ & $68(31,4)$ & $111(30,6)$ \\
\hline Correta & $5(3,4)$ & $7(3,2)$ & $12(3,3)$ \\
\hline Incompleta & $95(65,1)$ & $137(63,1)$ & $232(63,9)$ \\
\hline Não responderam & $3(2,1)$ & $5(2,3)$ & $8(2,2)$ \\
\hline \multicolumn{4}{|c|}{ O que os estudantes consideram maus-tratos infantis } \\
\hline Violência física & $141(96,6)$ & $216(99,5)$ & $357(98,4)$ \\
\hline Violência psicológica & $141(96,6)$ & $215(99,1)$ & $356(98,1)$ \\
\hline Negligência & $117(80,1)$ & $190(87,6)$ & $307(84,6)$ \\
\hline Abandono & $133(91,1)$ & $206(94,9)$ & $339(93,4)$ \\
\hline Abuso sexual & $140(95,9)$ & $213(98,1)$ & $353(97,2)$ \\
\hline Outros & $4(2,7)$ & $9(4,1)$ & $13(3,6)$ \\
\hline
\end{tabular}


Tabela 3 - Questões relacionadas à identificação de maus-tratos infantis pelos estudantes

\begin{tabular}{|c|c|c|c|}
\hline \multirow{2}{*}{ Sente-se capaz de identificar maus-tratos? } & Lages & Vitória & Total \\
\hline & n $\quad(\%)$ & n $(\%)$ & n $\quad(\%)$ \\
\hline Sim & $126(86,3)$ & $189(87,1)$ & $315(86,8)$ \\
\hline Não & $20(13,7)$ & $23(10,6)$ & $43(11,8)$ \\
\hline Não responderam & 0 & $5(2,3)$ & $5(1,4)$ \\
\hline \multicolumn{4}{|c|}{ Características que podem sinalizar maus-tratos: } \\
\hline Alterações comportamentais & $127(86,9)$ & $196(90,3)$ & $323(88,9)$ \\
\hline Lesões sem explicação & $11(7,5)$ & $13(5,9)$ & $24(6,6)$ \\
\hline Machucados no corpo e na face & $95(65,1)$ & $164(75,6)$ & $259(71,3)$ \\
\hline Falta de cuidado com a criança & $6(4,1)$ & $23(10,6)$ & $29(7,9)$ \\
\hline Outros & $4(2,7)$ & $12(5,5)$ & $16(4,4)$ \\
\hline \multicolumn{4}{|c|}{ Características bucais relacionadas aos maus-tratos } \\
\hline Dentes fraturados & $68(46,6)$ & $108(49,8)$ & $176(48,5)$ \\
\hline Falta de cuidados com a saúde bucal & $43(29,4)$ & $84(38,7)$ & $127(34,9)$ \\
\hline Lesões nos tecidos moles bucais & $81(55,5)$ & $156(71,9)$ & $237(65,3)$ \\
\hline Hábitos deletérios & $17(11,6)$ & $14(6,4)$ & $31(8,5)$ \\
\hline Não responderam & $10(6,8)$ & $9(4,1)$ & $19(5,2)$ \\
\hline
\end{tabular}

Tabela 4 - Conduta frente à situação de maus-tratos, conhecimento do ECA e responsabilidade do cirurgião-dentista frente aos maus-tratos

\begin{tabular}{|c|c|c|c|}
\hline \multirow{2}{*}{ Como agir diante de caso de maus-tratos? } & Lages & Vitória & Total \\
\hline & n $(\%)$ & n $\quad(\%)$ & n $\quad(\%)$ \\
\hline Denunciar ao Conselho Tutelar & $58(39,7)$ & $52(23,96)$ & $110(30,3)$ \\
\hline Denunciar à Delegacia da Infância e Adolescência & $4(2,7)$ & $24(11,05)$ & $28(7,7)$ \\
\hline Denunciar as autoridades & $64(43,8)$ & $80(36,86)$ & $144(39,7)$ \\
\hline Outros & $14(9,6)$ & $37(17,05)$ & $51(14,1)$ \\
\hline Nao responderam & $7(4,8 \%)$ & $64(29,5 \%)$ & $71(19,6 \%)$ \\
\hline \multicolumn{4}{|l|}{ Sabe o que é o ECA? } \\
\hline Sim & $55(37,7)$ & $73(33,6)$ & $128(35,3)$ \\
\hline Não & $91(62,3)$ & $140(64,5)$ & $231(63,6)$ \\
\hline Não responderam & 0 & $4(1,9)$ & $4(1,1)$ \\
\hline \multicolumn{4}{|l|}{$\mathrm{O}$ significado de ECA } \\
\hline Correto & $55(37,7)$ & $74(34,1)$ & $129(35,5)$ \\
\hline Incorreto & $91(62,3)$ & $143(65,9)$ & $234(64,5)$ \\
\hline \multicolumn{4}{|l|}{ Presenciou algum caso de maus-tratos? } \\
\hline Sim & $23(15,7)$ & $60(27,6)$ & $83(22,9)$ \\
\hline Não & $122(83,6)$ & $156(71,9)$ & $278(76,6)$ \\
\hline Não respondeu & $1(0,7)$ & $1(0,5)$ & $2(0,5)$ \\
\hline \multicolumn{4}{|l|}{ O Dentista tem responsabilidade de denunciar? } \\
\hline Sim & $143(97,9)$ & $208(95,9)$ & $351(96,7)$ \\
\hline Não & $3(2,1)$ & $7(3,2)$ & $10(2,8)$ \\
\hline Não respondeu & 0 & $2(0,9)$ & $2(0,5)$ \\
\hline \multicolumn{4}{|l|}{ Quer mais informações sobre o assunto? } \\
\hline Sim & $142(97,3)$ & $203(93,5)$ & $345(95,1)$ \\
\hline Não & $4(2,7)$ & $14(6,5)$ & $18(4,9)$ \\
\hline
\end{tabular}




\section{DISCUSSÃO}

Os maus-tratos na infância e adolescência ainda estão em evidência pela alta incidência na população. Preparar os profissionais que trabalham com saúde e com crianças é fundamental a fim de que este tipo de violência possa ser diagnosticado, prevenindo e evitando sua perpetuação. Neste contexto, destacam-se os acadêmicos de cursos de Odontologia, pois serão profissionais que atuarão no setor público e privado, com crianças e adolescentes tendo contato próximo também comsua família ${ }^{9}$.

Atualmente, o tema maus-tratos é abordado de várias formas, sendo que as campanhas de denúncia são as mais comuns. Apesar disto 34,9\% dos alunos afirmaram não ter recebido nenhuma informação sobre maus-tratos na infância e adolescência. Dos acadêmicos que receberam informação, a maioria citou os meios de comunicação (televisão, internet, palestras) como fonte das informações, o que pode ser um reflexo das campanhas realizadas no Brasil. Observou-se também que apenas 67 acadêmicos $(18,5 \%)$ que participaram do estudo relataram receber estas informações no curso de graduação. Deve-se notar que dentre estes, 10 alunos receberam informações nos primeiros três anos de curso e o restante (57 alunos) nos dois últimos anos, possivelmente porque as disciplinas que abordam este tema são ministradas após a metade do curso (Odontopediatria, Saúde Coletiva, Odontologia Legal). Embora no presente estudo menor número de alunos $(18,5 \%)$ relataram que a fonte de informações de violência infantil ocorreu no curso de Odontologia quando comparados com outros estudos, como o de Serpa e $\operatorname{Ramos}^{10}$ (30\%) e de Souza et al. ${ }^{11}(89,8 \%)$, vale ressaltar que no primeiro os alunos consideraram que as informações obtidas a respeito de maus-tratos na infância contribuíram para sua conduta diante da vítima.

Se por um lado o estudo mostrou que a graduação agregou conhecimentos aos alunos, também evidenciou a necessidade de inserção precoce deste tema nos currículos dos cursos de Odontologia, de maneira vertical e horizontal, com integração multidisciplinar ${ }^{9,11,12}$.

Como parâmetro para avaliação da definição de maus-tratos foi utilizado o conceito que consta no
Código Penal Brasileiro, por ser acessível e ter sido utilizada em outros estudos ${ }^{11,13}$. Foram consideradas incorretas quando os alunos apenas citavam a vilolência de forma vaga e abrangente ("criança que apanha", ou "criança que sofre violência"), incompleta quando o aluno citava várias formas de violência, mas esquecia de alguma ou da relação de poder do agressor, e foram consideradas completas as respostas que abordavam todos os pontos do Código Penal Brasileiro ${ }^{14}$. Com exceção de 8 alunos $(2,2 \%)$, ficou evidente que os acadêmicos apresentaram um conceito sobre maus-tratos, embora o mesmo esteja baseado no senso comum.

Quando foram questionados sobre o que consideram maus-tratos em uma questão de múltipla escolha, verificou-se que a maioria dos alunos assinalou todas as alternativas, sendo que a violência física, psicológica, sexual e abandono foram citados por mais de $90 \%$ dos participantes da pesquisa. Devese salientar que $15,4 \%$ dos participantes não consideraram a negligência como forma de maustratos. Segundo Pires ${ }^{1}$ e Kellogg ${ }^{15}$ a negligência é a forma mais comum de maus-tratos, muito embora fique mascarada por não deixar marcas físicas e psicológicas evidentes.

Outras formas de maus-tratos foram citadas pelos alunos, como o trabalho infantil e não ir à escola, evidenciando que alguns apresentam um conhecimento mais aprofundado sobre o assunto. A maioria dos alunos (86,8\%) sente-se capaz de diagnosticar casos de maus-tratos citando caracterísiticas gerais como alterações comportamentais, destacando timidez, medo, isolamento, algumas vezes a agressividade, não gostar de ser tocado, medo de adultos, dados bem superiores ao encontrado por Serpa e Ramos ${ }^{10}$.

Os sinais físicos de forma geral, tais como hematomas e escoriações, principalmente na face, foram citados por $71,3 \%$ dos alunos. Vale ressaltar que alguns destacaram situações bem características de maus-tratos como presença de hematomas atrás da orelha, marcas de queimaduras, áreas com alopécia e lesões características de doenças sexualmente transmissíveis. De acordo com dados da literatura, 50 a $65 \%$ das lesões físicas presentes nos casos de maustratos infantis ocorrem na face e cavidade oral ${ }^{16,17}$. 
De acordo com Cavalcanti $(2001)^{18}$, embora as lesões físicas sejam mais evidentes, estas não podem ser avaliadas isoladamente para o diagnóstico de maus-tratos, mas baseadas na anamnese, em relação à etiologia do trauma e nas características de evolução da lesão. Cavalcanti (2003) ${ }^{19}$ e Avon (2005) ${ }^{20}$ destacam que esta avaliação detalhada também deve ocorrer com a presença de petéquias e equimoses na região oral, que podem ou não estar relacionadas a doenças sexualmente transmissíveis, sendo que este sinais também foram citados pelos acadêmicos desta pesquisa como possíveis alterações que sugerem maus-tratos.

A falta de cuidados com a criança é evidenciada por Pires (2005) ${ }^{1}$, Vieira, Katz e Colares $(2008)^{21}$ e pela ABRAPIA $(2001)^{22}$, sendo considerada a forma mais comum de maus-tratos, incluindo negligência física (ausência de cuidados médicos, abandono e expulsão da criança de casa, ausência de alimentação, cuidados de higiene, vestimenta adequada e ambiente inseguro) e a negligência emocional que é a falta de suporte emocional, afetivo e de atenção. Nesta pesquisa 29 (7,9\%) dos acadêmicos citam a falta de cuidados como sendo uma característica geral de maus-tratos, destacando o descuido com a higiene geral.

Especificamente em relação às características bucais relacionadas aos maus-tratos, os alunos citaram alterações nos tecidos moles $(65,3 \%)$, como hematomas, lacerações principalmente nos lábios e palato. Os traumas dentários com presença de fratura foram citados por $48,5 \%$, o que vem de encontro com a literatura que cita que lesões dentárias como dentes fraturados, deslocados, com mobilidade ou avulsionados, raízes residuais múltiplas sem história plausível para esclarecer os ferimentos podem ser sinais evidentes de violência contra crianças ${ }^{18,20}$.

A negligência dental foi caracterizada pela falta de cuidados com a higiene bucal, elevado número de lesões de cárie e deixar a criança com dor. Sendo que dois alunos citaram a negligência dental como a situação onde o responsável sabe das condições desfavoráveis de saúde bucal da criança e não procura atendimento, demonstrando um conhecimento diferenciado sobre esta forma de maus-tratos, evidênciando o conceito apresentado pela $\mathrm{AAPD}^{23}$.
A presença de hábitos deletérios como morder bochechas e lábios, roer unha, arrancar cabelo e bruxismo, destacados por Ramos-Nitani e Bonassi em $2011^{24}$, também foi citada por 8,5\% dos alunos, sendo que alguns relacionaram esta alteração com as características psicológicas da criança.

Como os maus-tratos são um problema de saúde pública eles devem ser acertadamente diagnosticados e prevenidos; e neste processo a denúncia é fundamental. O Código Penal Brasileiro e o ECA determinam que casos suspeitos e/ou confirmados de maus-tratos devem ser denunciados ao Conselho Tutelar. Nesta questão a maioria dos alunos demonstrou conhecimento da necessidade de denunciar ao conselho tutelar, e alguns às autoridades de forma inespecífica, sugerindo conhecimento com base no senso comum. Como se tratava de uma pergunta aberta, os acadêmicos puderam indicar mais de uma ação quando diante de maus-tratos, ou mesmo não respondê-la $(19,6 \%)$. Vale lembrar que nesta amostra apenas 30,3\% referem o Conselho Tutelar, já nos estudos de Serpa e Ramos (2011) ${ }^{10}$ e Gomes et al. $(2011)^{13}$ houve um maior conhecimento.

Em relação ao ECA, apenas $35,3 \%$ dos alunos sabem o que é, qual o seu significado, sendo que o mesmo foi criado em $1990^{5}$, e está acessível para a população. Este resultado reflete que nem mesmo os cursos de graduação apresentam este estatuto para os acadêmicos.

Apenas 22,9\% dos alunos afirmamam ter presenciado situações de maus-tratos e mais de $96,7 \%$ reconhecem a responsabilidade do $\mathrm{CD}$ em denunciar. Esta informação está no Código Penal, mas não está explícita no Código de Ética Odontológico, sendo que Serpa e Ramos $^{10}$ e Matos et al. ${ }^{9}$ já sugeriram sua inclusão.

Diante destes dados é necessário salientar que informações sobre maus-tratos devem ser inseridas precocemente na graduação. De maneira geral, os dados obtidos em Lages foram semelhantes aos de Vitória, revelando que os currículos de Odontologia seguem eixos comuns. A maioria das informações foi obtida antes da graduação e durante o curso, subsidiando o aluno nesta questão que vai além da universidade, extrapolando suas ações no convívio social. Desta maneira, o conhecimento dos alunos 
deve ser construído de maneira multidisciplinar e ser aprofundado de acordo com suas vivências, a fim de que haja sedimentação do mesmo ${ }^{9,12}$.

\section{CONCLUSÃO}

Os alunos de ambas as instituições conseguem identificar sinais de maus-tratos. Embora a maioria dos acadêmicos conheça a necessidade de denunciar estas situações, aproximadamente um terço $(30,3 \%)$ citou o Conselho Tutelar, necessitando de mais informações sobre este processo. De forma geral, a universidade colabora com o conhecimento dos acadêmicos sobre o tema maus-tratos na infância e adolescência, entretanto sugere-se que este assunto deve ser abordado de forma mais específica e já nos primeiros anos do curso de graduação em Odontologia.

\footnotetext{
ABSTRACT

Child Abuse from the perspective of Dental Students Violence against children does not occur only in developing countries and happens so frequently that it is sometimes trivialized. Children and adolescents are easy targets for acts of violence because they are frail and dependent. The aim of this study was to verify the knowledge of dental students, by means of questionnaires, regarding maltreatment in childhood and adolescence. Application of a questionnaire to dental students enrolled in the Dentistry course of the University of Planalto Catarinense and Federal University of Espírito Santo, with an approach to the concept and characteristics of maltreatment, conduct when faced with this, knowledge about the Child and Adolescent Statute (CAS), and the dentist's responsibility about notification of maltreatment. The data were analyzed by means of descriptive statistics in absolute frequencies and percentages. In the research, 363 students participated. Of these 265 $(73 \%)$ were of the female gender, and the mean age was 21.38 years $( \pm 3.01)$. During the undergraduate period, $34,9 \%$ of the students affirmed they had not received any information about maltreatment in childhood and adolescence, and despite this, the majority $(86,8 \%)$ felt they were capable of diagnosing cases of maltreatment. The students mentioned alterations in soft tissues $(65,3 \%)$, dental traumas $(48,5 \%)$, as characteristics related to maltreatment. Regarding making a complaint/pressing charges, only $30,3 \%$ mentioned the Guardian Council and 35,3\% knew the meaning of "CAS". It was observed that
}

students from the two Institutions could identify signs of maltreatment, but they needed more information about the notification of these events.

Descriptors: Child Abuse. Dental Education. Dental Students.

\section{REFERÊNCIAS}

1. Pires ALD, Miyazaki MCOS. Maus-tratos contra crianças e adolescentes: revisão da literatura para profissionais da saúde. Arq Ciênc Saúde. 2005;(1):42-9.

2. Ramos MLCO, Silva AL. Estudo sobre a violência doméstica contra a criança em Unidades Básicas de Saúde do município de São Paulo, Brasil. Saúde Soc. 2011;20(1):136-46.

3. UNICEF 2012. Infância e adolescência no Brasil. [Acesso em: 29 fev. 2016]. Disponível em: http://www.unicef.org/brazil/pt/activitie.

4. Secretaria Nacional de Promoção dos Direitos da Criança e do Adolescente. [Acesso em: $28 \mathrm{fev}$. 2016]. Disponível em http://www.direitos dacrianca.org.br/midiateca/publicacoes/relatorio -geral-do-disque-100-2010.

5. Brasil. Lei no.8069, de 13 de julho de 1990. Dispõe sobre o Estatuto da Criança e do Adolescente e dá outras providências. [Acesso em: 2 fev. 2016]. Disponível em http://www.pla nalto.gov.br/ccivil/LEIS/L8069.htm.

6. Azevedo MS, Goettems ML, Brito A, Possebon AP, Domingues J, Demarco FF. Child maltreatment: a survey of dentists in southern Brazil. Braz Oral Res. 2012; 26(1):5-11.

7. Massoni ACLT, Ferreira AMB, Aragão AKR, Menezes VAC, Colares V. Aspectos orofaciais dos maus-tratos infantis e da negligência odontológica. Ciênc Saúde Coletiva 2010;15(2): 403-10.

8. Greco R. Código Penal Comentado. 10 ed. Niterói: Impetus; 2016. 1263p.

9. Matos FZM, Borges AH, Mamede Neto I, Rezende CD, Silva K, Pedro FLM, et al. Avaliação do conhecimento dos alunos de graduação em odontologia $\mathrm{x}$ cirurgiões-dentistas no diagnóstico de maus-tratos às crianças. Rev Odontol Bras Central. 2013;22(63):153-7. 
10. Serpa EM, Ramos AAS. Percepção dos maus tratos infantis pelos estudantes de odontologia da UFPB. Int J Dent. 2011;10(4):234-41.

11. Sousa GFP, de Carvalho MMP, GranvilleGarcia AF, Gomes MNC, Ferreira JMS. Conhecimento de acadêmicos em odontologia sobre maus-tratos infantis. Odonto. 2012; 20(40):109-17.

12. Thomas JE, Straffon L, Inglehart MR. Knowledge and professional experiences concerning child abuse: an analysis of provider and student responses. Ped Dent. 2006; 28(5):438-44.

13. Gomes LS, Pinto TCA, Costa EMMB, Ferreira JMS, Cavalcanti SDLB, Granville-Garcia AF. Percepção dos acadêmicos de odontologia sobre os maus tratos na infância. Odont Clin-Cient. 2011;10(1):73-8.

14. Brasil. Constituição da República Federativa do Brasil de 1988. [Acesso em: 2 fev. 2016]. Disponível em http://www.planalto.gov.br/ ccivil_03/Constituicao.

15. Kellogg ND. Evaluation of suspected child physical abuse. Pediatrics. 2007;119(6):1232-41.

16. Manea S, Favero GA, Stellini E, Romoli L, Mazzucato M, Facchin P. Dentists' perceptions, attitudes, knowledge, and experience about child abuse and neglect in Northeast Italy. J Clin Ped Dent. 2007;32(1):19-25.

17. Cavalcanti AL. Prevalence and characteristics of injuries to the head and orofacial region in physically abused children and adolescents--a retrospective study in a city of the Northeast of Brazil. Dent Traumatol. 2010; 26(2):149-53.
18. Cavalcanti AL. Abuso infantil: protocolo de atendimento odontológico. Rev Bras Odontol. 2001;58(6):378-80.

19. Cavalcanti AL. Manifestações físicas do abuso infantil: aspectos de interesse odontológico. Rev Paul Odontol. 2003; 25(5):16-9.

20. Avon, SL. Forensic Odontology: the roles and responsibilities of the dentist. J Can Dent Assoc. 2004;70(7):453-8.

21. Vieira ELR, Katz CRT, Colares V. Indicadores de maus-tratos em crianças e adolescentes para uso na prática da odontopediatria. Odont ClinCient. 2008; 7(2):113-8.

22. Associação Brasileira Multiprofissional de Proteção à Infância e à Adolescência/ ABRAPIA. Maus-tratos contra crianças e adolescentes: proteção e prevenção. Guia de orientação para profissionais da saúde. Rio de Janeiro. 2001.

23. American Academy of Pediatric Dentistry. Guideline on oral and dental aspects of child abuse and neglect. Ped Dent. 2013/2014; 35(6):163-6.

24. Ramos Nitani ON, Bonassi SM. Abuso sexual contra crianças: diagnóstico psicológico pericial sob o olhar psicanalítico. An Sciencult. 2011;1(3). [Acesso em: 2 fev. 2016]. Disponível em http://anaisonline.uems.br/ index.php/sciencult/article/view/3321/3294.

Correspondência para:

Claudia de Abreu Busato

e-mail: caiabusato@ hotmail.com

Rua Vidal de Negreiros, 181/12

88509-074 Lages/SC 